\title{
Infiltration Strategies of Mathematical Culture in Improving the Mathematical Literacy of Primary School Students
}

\author{
Deyang Fang* \\ Chongqing Second Normal University, Chongqing 400064, China \\ *Corresponding author: Deyang Fang, 1661071372@qq.com
}

\begin{abstract}
Primary schools are a sanctuary for basic education. Primary school students are in the initial stage of development in many areas. Mathematical culture has a great effect on the improvement of students' mathematical literacy. However, examoriented education has seriously affected people's way of thinking, leading to a large gap in mathematics education and its culture with excessive emphasis on the accumulation of mathematical knowledge, skill training, and other aspects but neglecting the cultural connotation of mathematics itself. Ensuring that students master mathematical knowledge is one of the purposes of mathematics education. However, while gaining knowledge, students should be guided to understand its cultural connotation. Therefore, in order to implement the concept of people-oriented education and promote the comprehensive development of students, it is extremely important to integrate mathematical culture into the cultivation of mathematical literacy.
\end{abstract}

Keywords: Mathematics literacy; Infiltration of mathematical culture; Primary education

Publication date: June 2021; Online publication: June 30, 2021

\section{Introduction}

With the pace of education reform in mathematics and the progress of mathematical culture, there has been a gradual exploration of the relationship between mathematical culture and the quality of mathematics education by several teachers in this field. Articles and reports pertaining the relationship have continued to emerge, setting off waves of education boom. The results from the research on mathematical culture, conducted by professional scholars, are mainly reflected in middle and higher education. It is rare to see those results in primary education although primary education is the starting point of each student. Therefore, the development of mathematical culture, which is worthy of attention and in-depth exploration, should begin from the initial stage.

\section{Assisting primary school students to understand the essence of mathematical culture}

The mathematics textbooks in primary schools contain many mathematical culture elements. If these elements can be infiltrated into the process of improving students' mathematics literacy, the education would in turn become more vivid, interesting, and closer to life, thus stimulating students' interest in learning mathematics. China's "5000 years of history" contains rich mathematical culture. Throughout the years, many great mathematicians have been born. By helping students understand the history and events related to mathematics, students would eventually recognize that mathematical knowledge is closely related to the things going on in daily life, such as counting. In the learning process, students would be more active in their participation and interested in learning. 
What is the difference between mathematics and other subjects? There is no cultural connotation in mathematics. In view of this situation, primary school teachers should carry out psychological counseling, reasonably eliminate the wrong idea, and correct the cognition of students so that students can begin to appreciate the mathematical culture contained in the education as well as realize the close relationship between mathematics and daily life. For example, during the lesson of year, month, and day in the third grade, it is crucial to assist students to intuitively realize the essence of year, month, and day in their daily lives. This in turn would provide an opportunity for students to acknowledge that there are a lot of mathematical knowledge in social culture, thus forming a new cognitive thought among students and allowing them to better understand mathematics. The cultural heritage of the subject itself can improve students' interest and enthusiasm in learning mathematics ${ }^{[1]}$.

\section{Improving mathematical literacy by strengthening cognitive knowledge structure}

The process from the discovery of mathematical knowledge to the recognition of mathematical knowledge is known as the process of mathematical knowledge formation. Each and every mathematical knowledge point is formed with a special historical background. Therefore, it is important to help students acquire mathematical knowledge in the learning process. In addition, students should be encouraged to maintain a positive attitude during the whole learning process in order to understand mathematical knowledge and improve their learning skills. Therefore, while carrying out mathematics lessons, situational education can be applied by explaining the development and formation process of mathematics with the aid of real cases so that students can explore and look for problems in it. By understanding the exploration and formation process of mathematics, students can develop an overall and comprehensive understanding of a specific topic. For example, during the lesson of triangle in the fourth grade, students would have a more comprehensive and in-depth understanding of the formation and development of triangles through situational education, and with the understanding of the development process of mathematics, they can intuitively appreciate the composition and development of the shape in the future, as well as understand the application of mathematics in specific events of daily life and social progress. Students would eventually realize the value and function of mathematics with the formation of correct mathematical concepts and ideas ${ }^{[2]}$.

\section{Cultivating mathematical literacy by enhancing the use of activities}

Mathematical culture can be widely applied; therefore, teachers can rely on vivid and interesting educational activities to ensure primary school students would come to understand mathematical culture. For primary school students, their favorite classroom activities are competition-like activities and games. Therefore, using either one of the two methods may help students understand mathematical culture. In the process of imparting mathematical knowledge, the designed questions should be inclined to mathematical culture. Recognition and rewards should be given to students who are able to answer those questions. In addition, students should also be given the opportunity to prepare questions for the next class. The questions should also be closely related to mathematical culture. Through this method, students can effectively improve their initiative in learning mathematical culture and the goal of more effective mathematical literacy training can be achieved. Every student's daily life is full of things and matters that are related to mathematics. For example, during the lesson of location in the fifth grade, teachers should help students understand the extensive use of location in the real world so that students can appreciate the value and role of location in their daily lives. In that way, students would develop a comprehensive and in-depth understanding of the value of mathematics ${ }^{[3]}$. 


\section{Cultivating mathematical literacy from the aesthetic perspective of mathematical figures and formulas}

Figures and formulas in mathematics fully present the charm of mathematical culture with to their own characteristics: simplicity, particularity, and regularity. It is understood that the sustainable and efficient progress as well as the development of mathematics are largely due to the charm of mathematical culture itself. In daily lessons, students should be guided to pay attention to mathematical symbols, formulas, and graphics, which reflect the simple, particular, regular, and symmetrical characteristics of mathematical culture, thus forming the aesthetic concept of the students' own mathematical culture. Learning mathematics does not only effectively exercise students' logical thinking, but also their aesthetic ability and creativity. During mathematics lessons, it is essential to pay attention to the cultivation of students' mathematical literacy through the rich cultural content contained in its curriculum, explore the mathematical knowledge, skills, values, and aesthetic concepts in its textbooks, as well as improve on the existing basis so that students' mathematical literacy can be cultivated in a mathematical cultural environment. For example, during the lesson of graphics movements in the fourth grade, teachers can play sports-related videos in relation to the topic using multimedia in order to cultivate students' aesthetic ability and innovative skills. Through this method, their knowledge reserve can be ensured while continuously cultivating their mathematical literacy and improving their mathematical skills. This would lay a solid foundation for students' daily lives and careers in the future as well as promote their comprehensive development.

\section{Stimulating the desire to learn through mathematical culture}

In primary school mathematics education, teachers should explore and educate the students about the historical figures or events related to mathematics so that students can realize how to use mathematical knowledge to solve problems from the long historical process of countless mathematical learning, face difficulties, and obtain admirable achievements. In that way, when students are in face of difficulties, they would be able to solve them. While carrying out in-depth exploration of the historical inspirational figures and mastering real experience of mathematical creation, students would be able to perceive the law of mathematical development in the process of gradual progress as well as enhance their self-confidence and courage in exploring mathematical problems.

For example, in understanding abacus, teachers can create a real historical process with an ancient charm from the origin of abacus, the development of computing tools, the advantages and disadvantages of abacus at all times and in all countries, and so on. Every link is full of mathematical culture; thus, the classroom design can be very effective to attract the attention of primary school students. During lesson preparations, teachers should be fully prepared in terms of the cultural knowledge of mathematics that is related to the topic. They should deeply explore the cultural history of mathematics contained in the knowledge points and present it in a vivid or interesting way during their lessons. In traditional mathematics education, there are repeated trainings in regard to abacus and memorizing the pithy formula. This is the essential reason why students lose interest in abacus. By reasonably guiding students to understand mathematical culture ensues their escape from the boring education process of the past; instead, it allows them to explore problems with interest. How then can this process affect the students? Several students have shared their feelings after their lessons: "Abacus used to have such great value in ancient times. There will be new computing tools constantly developed and created in the future. Human beings are so smart! I also want to be a mathematician!"; "In the past, I have always thought that mathematics was to write numbers and solve problems but now my learning has changed my point of view. It turns out that mathematics can be so interesting!"; "I hope that future mathematics lessons can introduce more vivid and interesting stories so that students can learn more about mathematical culture." Upon listening to their 
feelings, mathematics education does not only train students to write and calculate, but also in humanity and vividness. As long as there are deep explorations and careful designs, students would be able to realize the charm of mathematical knowledge ${ }^{[4]}$.

\section{Conclusion}

Mathematical culture, like other types of culture, is one of the key components for the development of social civilization. According to its own special cultural connotation, it stimulates students' yearning for mathematics, their sense of mission to contribute to the society in the process of understanding the great achievements of mathematics, and their interests to explore its connotation in feeling the charm of mathematics. In addition, it exercises students' practical skills and innovative spirit in the process of applying mathematical knowledge to solve problems and pursues the development of mathematical thinking in order to improve students' mathematical literacy, thus forming a scientific and meticulous attitude as well as a persistent spirit.

\section{Disclosure statement}

The author declares that there is no conflict of interest.

\section{References}

[1] Liu H, 2020, Building Mathematics Classroom Culture to Improve Primary School Students' Mathematics Literacy. Progress: Teaching and Research, (1): 124.

[2] Qian P, Ren S, 2019, Make Good Use of Mathematical Culture to Promote Core Literacy and Open Quality Life - Research on the Infiltration Strategy of Mathematical Culture in Senior High School Mathematics Teaching. Test Questions and Research, (28).

[3] Cai Y, 2020, Infiltrating Mathematical Culture to Cultivate Core Literacy: Integrating Mathematical Culture is the Value Pursuit of High School Mathematics Teaching. Middle School Teaching and Research: Mathematics Edition, (1): 11-15.

[4] Xu Y, 2019, Mathematical Culture and Primary School Mathematics Classroom Teaching Based on the Improvement of Students' Mathematics Literacy. Mathematics Learning and Research: Teaching and Research, (8): 55. 